\title{
Sympathetic mediated vasomotion and skin capillary permeability in diabetic patients with peripheral neuropathy
}

\author{
J. D. Lefrandt, E. Bosma, P. H. N. Oomen, J. H. Hoeven, A. M. Roon, A. J. Smit, K. Hoogenberg \\ Divisions of Angiology, Department of Internal Medicine, University Hospital, Groningen, The Netherlands \\ Department of Neurology, University Hospital, Groningen, The Netherlands \\ Department of Internal Medicine, Endocrinology and Diabetes, Martini Hospital, Groningen, The Netherlands
}

\begin{abstract}
Aims/hypothesis. A loss of sympathetic function could lead to changes in capillary fluid filtration in diabetic patients. We investigated whether a decreased sympathetically mediated vasomotion in the skin in diabetic patients with peripheral neuropathy is associated with an abnormal capillary leakage.

Methods. Three matched groups were studied: 18 diabetic patients with documented peripheral neuropathy (DN), 18 diabetic patients without peripheral neuropathy (D), and 18 healthy control subjects (C). Sensory and motor nerve function of the distal extremities were assessed by standard neurography, and expressed in a sensory-motor nerve function score. Sympathetic vasomotion of the skin microcirculation was assessed by determining the power of blood flow variability in the low-frequency $(0.02-0.14 \mathrm{~Hz})$ band by spectral analysis of laser Doppler flowmetry at the median ankle. Skin capillary leakage was evaluated by sodium fluorescein videodensitometry at the same site of the foot.
\end{abstract}

Results. Sympathetically mediated vasomotion of the foot skin microcirculation was lower in diabetic patients with documented peripheral neuropathy compared with diabetic patients without peripheral neuropathy and control subjects $(p<0.001)$. Capillary sodium fluorescein leakage was larger in 18 diabetic patients with documented peripheral neuropathy than in diabetic patients without peripheral neuropathy $(p<0.02)$ and $\mathrm{C}(p<0.005)$. Multiple regression analysis disclosed that a reduced sympathetically mediated vasomotion, together with a lower sensory-motor nerve function score, independently contributed to the variance in sodium fluorescein leakage, for $30 \%$ $(p<0.001)$ and $17 \%(p<0.01)$, respectively.

Conclusions. A loss of sympathetic tone, apart from sensory-motor nerve dysfunction, seems to be a major determinant of an increased capillary permeability in diabetic patients with neuropathy. [Diabetologia (2003) 46:40-47]

Keywords Blood flow, capillaries, sympathetically nervous system, diabetes mellitus.
The skin microcirculation is abundantly innervated by sympathetic nerves that regulate blood flow by opening and closing of arteriovenous anastomoses and pre-

Received: 1 July 2002 / Revised: 28 August 2002

Published online: 11 January 2003

C Springer-Verlag 2003

Corresponding author: K. Hoogenberg M.D. Ph.D., Department of Internal Medicine, Endocrinology and Diabetes, Martini Hospital, PO Box 30033, 9700 RM Groningen, The Netherlands. E-mail: k.hoogenberg@mzh.nl

Tel.: +31-50-3616875, Fax: +31-50-3615245

Abbreviations: $B F V$, blood flow variability; $L F$, low-frequency; $H F$, high-frequency; $N a F$, sodium fluorescein. capillary arterioles. Blood flow through the skin changes in a cyclical manner, known as vasomotion [1]. These oscillations are under sympathetic control, either directly through periodic nerve discharges or through facilitation of an endogenous vascular pacemaker $[2,3]$. The rhythmicity is considered to be a fundamental part of proper tissue perfusion [2, 3, 4], and a loss of sympathetically mediated vasomotion could derange fluid filtration at the capillary level.

In diabetic patients, sympathetic denervation as well as microcirculatory alterations have been described. A decrease in sympathetic tone $[5,6,7,8]$, an increase of capillary flow and pressure $[9,10,11]$ and an increase of capillary permeability $[12,13,14,15$, 
16] have been documented at various stages of the disease. The role of the sympathetic nervous system in the development of diabetes-associated microcirculatory alterations is not fully understood.

Spectral analysis of skin blood flow oscillations, recorded continuously by laser Doppler flowmetry, can be used to study sympathetically mediated vasomotion $[3,17,18]$. Sympathetic stimulation by postural change $[17,18]$ and sympathetic blockade by anesthetics [17], have the largest effect on the low-frequency (LF; 0.02 to $0.14 \mathrm{~Hz}$ ) power component of skin blood flow variability (BFV). The skin LF-BFV power has been shown to be lowered in diabetic patients [3]. Sodium fluorescein $(\mathrm{NaF})$ videodensitometry is used to study capillary permeability. With different visualizing techniques, an increased $\mathrm{NaF}$ leakage has been found in the capillary beds of the retina [19], the nailfold [12] and the foot skin [20] of diabetic patients. With an improved technique [21], we found that angiotensin-converting enzyme inhibitors, inde- pendent from its blood pressure lowering effect, reduced $\mathrm{NaF}$ leakage in microalbuminuric diabetic patients, suggesting that changes that at the microcirculatory level influence capillary $\mathrm{NaF}$ permeability [15].

In this study, we investigated the role of sympathetically mediated vasomotion on capillary permeability in diabetic patients with and without overt peripheral neuropathy and healthy control subjects by combining the laser Doppler based assessments of skin LF-BFV and the skin capillary $\mathrm{NaF}$ videodensitometry.

\section{Subjects, Materials and methods}

Characterization of patients and healthy subjects. The study was approved by the local medical ethics committee and written informed consent was obtained from all participants after explanation of the purpose of the study. Patients were recruited from the outpatient clinic of the University Hospital Groningen and the Rehabilitation Centre Beatrixoord. Healthy control subjects were recruited by an advertisement in a local newspa-

Table 1. Clinical characteristic of the study groups

\begin{tabular}{|c|c|c|c|}
\hline Study groups* & DN & $\mathrm{D}$ & $\mathrm{C}$ \\
\hline Number $(n)$ & 18 & 18 & 18 \\
\hline Age (years) & $57 \pm 3$ & $54 \pm 2$ & $58 \pm 2$ \\
\hline Sex (male/female) & $8 / 10$ & $8 / 10$ & $8 / 10$ \\
\hline BMI $\left(\mathrm{kg} / \mathrm{m}^{2}\right)$ & $29.3 \pm 1.2$ & $28.7 \pm 1.2$ & $27.3 \pm 1.3$ \\
\hline Type of diabetes (Type1/Type 2) & $4 / 14$ & $4 / 14$ & - \\
\hline Diabetes duration (years) & $18 \pm 3$ & $12 \pm 2$ & - \\
\hline Patients using insulin $(n)$ & 14 & 13 & - \\
\hline Insulin dose (IU/day) & $69 \pm 15^{\mathrm{a}}$ & $42 \pm 7$ & - \\
\hline Smokers $(n)$ & 9 & 6 & 5 \\
\hline Ankle-arm index & $1.16 \pm 0.05$ & $1.23 \pm 0.03$ & $1.20 \pm 0.03$ \\
\hline Toe pressure $(\mathrm{mmHg})$ & $129 \pm 7$ & $118 \pm 5$ & $123 \pm 4$ \\
\hline Plethysmographic crest time (s) & $0.19 \pm 0.03$ & $0.17 \pm 0.01$ & $0.16 \pm 0.02$ \\
\hline Glycated haemoglobin (\%) & $8.2 \pm 0.2^{\mathrm{b}}$ & $7.6 \pm 0.2^{\mathrm{b}}$ & $5.7 \pm 0.1$ \\
\hline Retinopathy (Absent/Background/Proliferative) & $3 / 11 / 4^{a}$ & $13 / 5 / 0$ & - \\
\hline Microalbuminuria $(n)$ & $9 \mathrm{c}$ & 1 & 0 \\
\hline Albumin/creatinine ratio $(\mathrm{mg} / \mu \mathrm{mol})$ & $17.6 \pm 10.9^{c}$ & $1.3 \pm 0.5$ & $0.8 \pm 0.1$ \\
\hline Serum creatinine $(\mu \mathrm{mol} / \mathrm{l})$ & $93.4 \pm 5.9$ & $87.6 \pm 2.7$ & $88.8 \pm 2.1$ \\
\hline Systolic/Diastolic Blood Pressure (mmHg) & $148 \pm 5 / 80 \pm 3$ & $136 \pm 3 / 79 \pm 1$ & $136 \pm 4 / 84 \pm 2$ \\
\hline Number of antihypertensives $(0 / 1 / 2)^{a}$ & $6 / 6 / 6^{d}$ & $11 / 5 / 2$ & $16 / 2 / 0$ \\
\hline ACE-inhibition therapy $(n(\%))$ & $10 / 18(55 \%)^{\mathrm{d}}$ & $6 / 18(30 \%)$ & $2 / 18(11 \%)$ \\
\hline Diabetic Neuropathy Examination score & $8.9 \pm 2.1^{\mathrm{c}}$ & $1.2 \pm 1.8$ & $0.5 \pm 1.6$ \\
\hline Semmes-Weinstein monofilaments & $6.60 \pm 0.12^{c}$ & $5.12 \pm 0.08$ & $5.12 \pm 0.08$ \\
\hline \multicolumn{4}{|l|}{ Foot: Sensory conduction $\mathrm{n}$ suralis } \\
\hline measurable & $9 / 18$ & $17 / 18$ & $18 / 18$ \\
\hline velocity $(\mathrm{m} / \mathrm{s})$ & $37.8 \pm 1.3^{\mathrm{c}}$ & $45.4 \pm 1.2$ & $47.5 \pm 0.7$ \\
\hline amplitude (mV) & $0.9 \pm 0.2^{\mathrm{c}}$ & $7.9 \pm 0.8$ & $11.0 \pm 1.8$ \\
\hline ranked scores & $10.5 \pm 1.4^{\mathrm{c}}$ & $33.9 \pm 2.4$ & $38.2 \pm 1.9$ \\
\hline \multicolumn{4}{|l|}{ Foot: Motor conduction n. peroneus (tibialis anterior) } \\
\hline Measurable & $18 / 18$ & $18 / 18$ & $18 / 18$ \\
\hline velocity $(\mathrm{m} / \mathrm{s})$ & $43.8 \pm 1.7 \mathrm{c}$ & $55.9 \pm 1.6$ & $55.1 \pm 1.5$ \\
\hline amplitude (mV) & $5.7 \pm 0.8^{\mathrm{c}}$ & $10.2 \pm 0.7$ & $9.8 \pm 0.8$ \\
\hline ranked scores & $14.6 \pm 2.1^{\mathrm{c}}$ & $35.6 \pm 2.4$ & $32.2 \pm 1.9$ \\
\hline Combined ranked sensory-motor responses & $12.6 \pm 1.4^{\mathrm{c}}$ & $34.7 \pm 2.0$ & $35.1 \pm 1.7$ \\
\hline
\end{tabular}

Data are given in means \pm SEM. * Groups DN, D and C, see text. ${ }^{a} p<0.05$ from $\mathrm{D},{ }^{\mathrm{b}} p<0.001$ from $\mathrm{C},{ }^{\mathrm{c}} p<0.001$ from D and C,

${ }^{\mathrm{d}} p<0.005$ from $\mathrm{D}$ and $\mathrm{C}$ 
per. The study consisted of three groups: 18 diabetic patients with peripheral neuropathy (DN), 18 diabetic patients without peripheral neuropathy (D), and 18 control subjects with normal glucose tolerance $(\mathrm{C})$. The groups were individually matched for age (within $5 \mathrm{yr}$ ), sex and body mass index (BMI, within $5 \mathrm{~kg} / \mathrm{m}^{2}$ ). The diabetic patients were matched for type of diabetes (Type 1 and Type 2). The results of the matching procedure are given in Table 1. The diabetes type was assessed on clinical grounds, and in the case of doubt by glucagon stimulated C-peptide concentrations. The proportion of diabetic patients using insulin was similar in $\mathrm{DN}$ and $\mathrm{D}$, although $\mathrm{DN}$ used higher doses than $\mathrm{D}(p<0.05$, Table 1$)$. Normal glucose tolerance in the control subjects was assessed by a blood glucose concentration less than $7.8 \mathrm{mmol} / \mathrm{l} 120 \mathrm{~min}$ after ingestion of 75 grams of glucose. The number of smokers was not different among the groups. Peripheral vascular disease was excluded in all participants by normal ankle-arm indexs $(>0.90)$, toe pressures $(>100 \mathrm{mmHg})$ and plethysmography (crest time $<0.22 \mathrm{~s}$, Table 1 ). Clinically apparent cardiac disease was excluded by history, and all had a normal resting electrocardiography, confirming sinus rhythm. Glycated haemoglobin concentrations indicated that the diabetic patients were in moderate metabolic control (Table 1). Neuropathy coincided with other diabetes associated complications since retinopathy was more severe $(p<0.05$ from $\mathrm{D}$, Table 1$)$ and the prevalence of microalbuminuria higher in DN $(p<0.001$ from $\mathrm{D}$ and $\mathrm{C}$, Table 1). Patients using $\alpha-, \beta$-adrenergic inhibitors or calcium antagonists were excluded. The use of angiotensinconverting enzyme inhibitors, angiotensin II receptor antagonists and diuretics was allowed. Although systolic and diastolic blood pressure did not differ, a higher proportion of patients in DN used antihypertensive medication $(p<0.005$, Table 1$)$. Patients with alcohol consumption of more than four units per day, hepatic and renal insufficiency, folic acid and hydroxycobolamin deficiencies were excluded.

Assessment of neuropathy. Diabetic neuropathy was diagnosed according to the San Antonio Consensus Statement criteria [22]. Clinical neuropathy signs were scored by means of the Diabetic Neuropathy Examination (DNE) score [23] that has a maximum score of 16 and is a modification of Neuropathy Disability Score [24]. Quantitative sensory testing was carried out with Semmes-Weinstein monofilaments. Motor nerve conduction velocities and amplitudes were measured in the peroneal nerve (tibialis anterior), and sensory nerve conduction velocities and amplitudes in the sural nerve [25]. Nerve conduction velocities and amplitudes of the peroneal and the sural nerve were ranked separately. The mean of the rank of the conduction velocity and the amplitude of these nerves, as well as the overall mean in ranks of both nerves, was calculated as indexes of motor nerve function, sensory nerve function and combined sensory-motor nerve function, respectively. The neuropathy scores are given in Table 1 . As expected from the selection criteria, severe neuropathy was present in the DN group, and no differences in neuropathy scores existed between the DC and C groups (Table 1).

Study protocol. The participants were studied in the morning, $11 / 2 \mathrm{~h}$ after breakfast during which the diabetic patients had taken their usual oral hypoglycaemic drugs or regular insulin injections. Blood glucose was measured at arrival, and at hourly intervals thereafter. Blood glucose concentrations ranging from 3.5 to $15.0 \mathrm{mmol} / \mathrm{l}$ were accepted during the studies. Subjects were instructed not to smoke or consume drinks containing caffeine $24 \mathrm{~h}$ before the study. They were studied in a supine position and allowed to acclimatize for $30 \mathrm{~min}$ to the

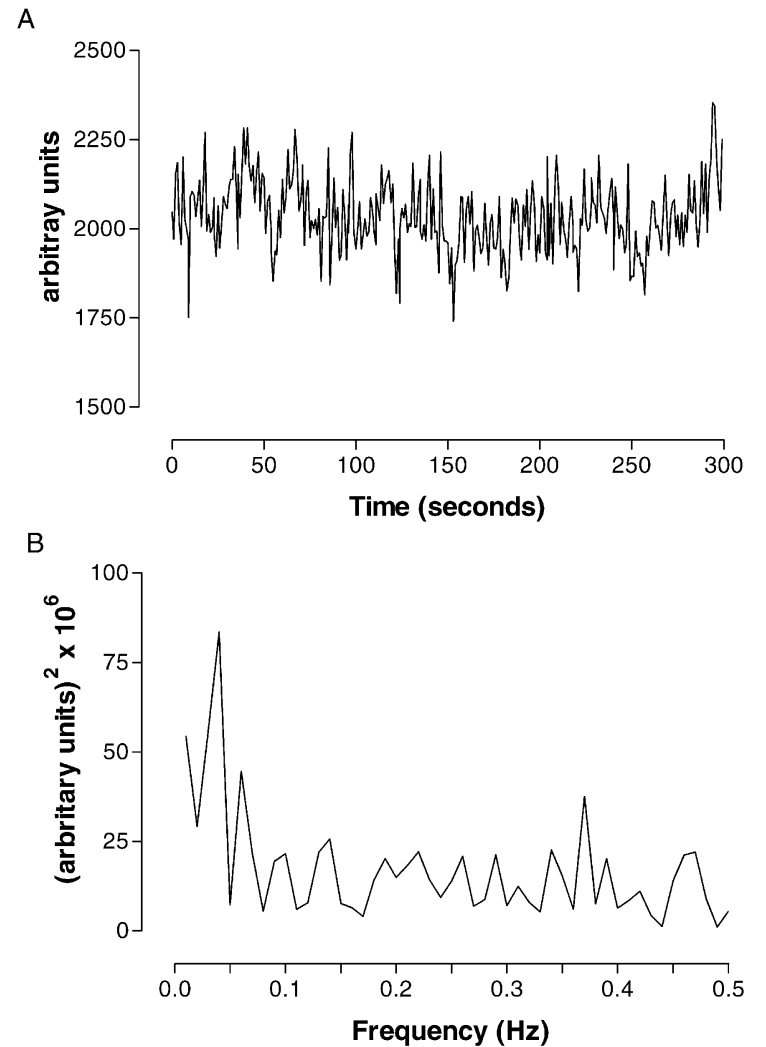

Fig. 1A, B. (A) 5 minutes of continuous skin blood flow recording by the laser Doppler flowmetry. (B) Power density spectrum of the changes in skin blood flow

environmental conditions of a quiet, temperature controlled room $\left(24^{\circ} \mathrm{C}\right)$. Ankle skin temperature was measured with a thermocouple (Ellab DU3-s, Copenhagen, Denmark), a skin temperature above $28^{\circ} \mathrm{C}$ was considered appropriate to start the measurements [10]. Blankets, covering the legs, were used to maintain the temperature at the desired level, while exogenous heating was avoided as this could influence skin blood flow oscillations.

Skin blood flow variability. Skin blood flow was measured at the median ankle with laser Doppler flowmetry (Diodopp, Applied laser technology, Asten, The Netherlands), which has been validated previously [26]. The probe was attached with double-sided adhesive tape at the medial malleolus. The laser Doppler flux signal (Fig. 1A), expressed in arbitrary units (AU), was recorded online for $10 \mathrm{~min}$ by a personal computer program (Poly, version 4.9, Inspektor Research Systems, Amsterdam, The Netherlands) with a sampling frequency of $100 \mathrm{~Hz}$, and stored on disk for analysis afterwards. Skin BFV was assessed by spectral analysis using the CARSPAN program (version 2.0, Progamma, Groningen, the Netherlands) $[27,28]$. The systolic component of the laser Doppler signal was taken for discrete Fourier transformation (Fig. 1b). The following spectral characteristics were obtained: the total BFV was the power in the 0.02 to $0.40 \mathrm{~Hz}$ frequency band ( $\mathrm{AU}^{2}$ ), the low-frequency (LF) BFV was the power in the 0.02$0.14 \mathrm{~Hz}$ frequency band ( $\left.\mathrm{AU}^{2}\right)$, and the high-frequency $(\mathrm{HF})$ $\mathrm{BFV}$ was the power in the $0.15-0.40 \mathrm{~Hz}$ frequency band $\left(\mathrm{AU}^{2}\right)$. The LF-BFV was also expressed in normalized units (NU), which represents the ratio between the LF-BFV power and total BFV power $[3,18]$. 

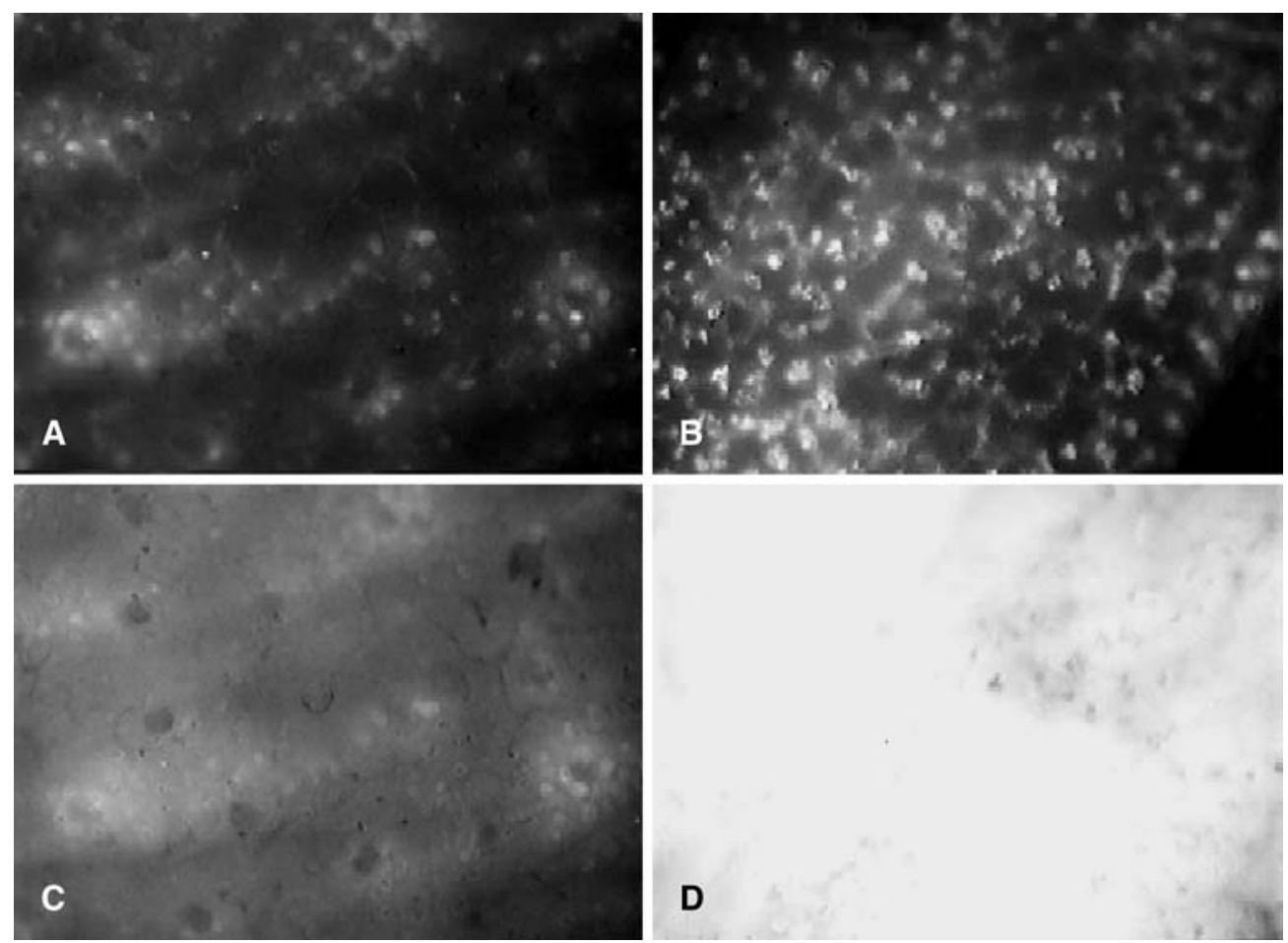

Fig. 2A-D. Sodium fluorescein $(\mathrm{NaF})$ videodensitometry images at the time of dye arrival in the skin capillaries in a healthy subject (A) and in a diabetic patient with peripheral neuropathy (B). Similar images after $60 \mathrm{~s}$ of interstitial $\mathrm{NaF}$ diffusion in a healthy subject $(\mathbf{C})$ and a diabetic patient with peripheral neuropathy $(\mathbf{D})$

Sodium fluorescence videodensitometry. Large-window $\mathrm{NaF}$ videodensitometry was carried out to measure skin capillary permeability. The system consists of an epiilumination microscope (Olympus BHMJ, Tokyo, Japan) to which a 75 watt xenon lamp is mounted (Osram XBO, Berlin, Germany). Emitted light is filtered using a fluorescence filter set (Olympus BH2-UDMB, excitation 380-490 nm, barrier $515 \mathrm{~nm}$, Tokyo, Japan). A $2 \times 3 \mathrm{~mm}$ section of the skin of the medial malleolus of the ankle was visualized (magnification $\times 100$ ), adjacent to the place where the LDF probe was situated. Immersion oil (Leitz, din 58884, Wetzlar, Germany) was applied to the skin to increase skin transparency. A bolus of $\mathrm{NaF}$ solution $[0.3 \mathrm{ml}$ of a $15 \% \mathrm{NaF}$ (MW 376) solution per litre of estimated blood volume] was injected intravenously. The epiillumination microscope visualizes the rapid capillary appearance (Fig. 2A) and the subsequent interstitial leakage of NaF (Fig. 2B). Images were continuously recorded for 20 min using a video camera (Grundig FA-85, Fürth, Germany), from which the automatic gain function had been removed, and a S-VHS video recorder (JVC HR-S7500E/EH, Japan). Every second, video images were digitized for analysis (Fig. 2). Total fluorescence light intensity of each image was expressed in arbitrary units (AU). Background fluorescence intensity was obtained from one baseline image and was subtracted from all subsequent intensities. To avoid the effects of differences in skin transparency and body composition between individuals, fluorescent light intensities were expressed as a percentage of individual maximal light intensity. The relative fluorescence values provided a semiquantitative way to describe $\mathrm{NaF}$ leakage curves. The intra-individual day-to-day reproducibility has a coeffi-

cient of variation of $10 \%$ [21]. The time interval between the $\mathrm{NaF}$ injection until appearance in the skin capillaries was defined as dye arrival time. Capillary density was measured by counting the visualized capillaries from the tape recordings after appearance of $\mathrm{NaF}$ in the skin capillaries (Fig. 2a).

Statistical analysis. Data are given as means \pm SEM. The natural $\log$ of the spectral powers of skin BFV were used for analyses since spectral parameters have a $\chi^{2}$-distribution that is normalized after log transformation [28]. Both the NaF leakage curves from 0 to $7 \mathrm{~min}$, as well as the area under the curve of the relative fluorescence intensity (denoted as AUC and the time after dye arrival in seconds) were analysed. One-way ANOVA with Bonferroni correction for multiple comparisons was used to analyse differences between the groups. Chisquare analysis was used to show differences in prevalence between the groups. Repeated ANOVA measurements, with Student Newmann Keuls correction for multiple comparisons, evaluated between group differences of the 0- to 7-min $\mathrm{NaF}$ leakage curves. Univariate correlations were expressed as Pearson's correlation coefficients. The independent contribution of variables was evaluated by stepwise multiple regression analysis. A double-sided $p$-value of less than 0.05 was considered statistically significant.

\section{Results}

The mean blood glucose concentration was higher in $\mathrm{D}$ and DN than in C $(p<0.001$, Table 2$)$. Skin temperature was higher in DN than in D and $\mathrm{C}(p<0.001$, Table 2). The total power BFV was lower in DN compared to $\mathrm{C}(p<0.01$, Table 2$)$. The LF-BFV power was lower in DN $(p<0.05$ from $\mathrm{D}$ and $p<0.005$ from $\mathrm{C})$, while the HF-BFV power was not different among the groups (Table 2). The differences in LF-BFV, the band of interest, were even more evident when expressed in 
Table 2. Spectral analysis parameters of skin blood flow variability (BFV) and skin capillary sodium fluorescein leakage

\begin{tabular}{|c|c|c|c|}
\hline Study groups* & $\mathrm{DN}$ & $\mathrm{D}$ & $\mathrm{C}$ \\
\hline Blood glucose during study (mmol/l) & $8.9 \pm 0.8^{\mathrm{a}}$ & $8.7 \pm 0.6^{\mathrm{a}}$ & $5.9 \pm 0.2$ \\
\hline Mean skin temperature $\left({ }^{\circ} \mathrm{C}\right)$ & $31.4 \pm 0.2^{b}$ & $30.4 \pm 0.3$ & $30.0 \pm 0.2$ \\
\hline Low-frequency power skin BFV $\ln \left(\mathrm{AU}^{2}\right)$ & $8.4 \pm 0.2^{\mathrm{a}, \mathrm{c}}$ & $9.1 \pm 0.2$ & $9.8 \pm 0.2$ \\
\hline High-frequency power skin $\mathrm{BFV} \ln \left(\mathrm{AU}^{2}\right)$ & $8.0 \pm 0.1$ & $7.7 \pm 0.2$ & $8.0 \pm 0.1$ \\
\hline Low-frequency BFV (NU) & $0.56 \pm 0.04^{b}$ & $0.77 \pm 0.04$ & $0.82 \pm 0.03$ \\
\hline Maximum fluorescence (AU) & $19601 \pm 3660$ & $23483 \pm 3743$ & $19351 \pm 2705$ \\
\hline $\mathrm{AUC}_{30 \mathrm{~s}}$ fluorescence curve after $30 \mathrm{~s}$ & $30.3 \pm 5.0^{\mathrm{a}, \mathrm{e}}$ & $13.8 \pm 2.7$ & $7.8 \pm 1.1$ \\
\hline $\mathrm{AUC}_{60 \mathrm{~s}}$ fluorescence curve after $60 \mathrm{~s}$ & $37.0 \pm 5.1^{\mathrm{a}, \mathrm{e}}$ & $20.6 \pm 3.0$ & $14.7 \pm 1.6$ \\
\hline $\mathrm{AUC}_{120 \mathrm{~s}}$ fluorescence curve after $120 \mathrm{~s}$ & $45.5 \pm 4.9^{\mathrm{a}, \mathrm{f}}$ & $30.5 \pm 3.0$ & $23.6 \pm 2.0$ \\
\hline $\mathrm{AUC}_{420 \mathrm{~s}}$ fluorescence curve after $420 \mathrm{~s}$ & $68.0 \pm 3.4 \mathrm{~g}$ & $60.3 \pm 2.1$ & $54.4 \pm 2.0$ \\
\hline
\end{tabular}

Data in means \pm SEM. * Groups DN, D and C, see text. Spectral power are natural logs. AUC, area under the curve at given time point. ${ }^{a} p<0.001$ from $\mathrm{C}$; ${ }^{\mathrm{b}} p<0.001$ from $\mathrm{D}$ and $\mathrm{C}$;
${ }^{\mathrm{c}} p<0.01$ from $\mathrm{C} ;{ }^{\mathrm{d}} p<0.05$ from $\mathrm{D}$ and $\mathrm{C},{ }^{\mathrm{e}} p<0.01$ from $\mathrm{D}$, f $p<0.05$ from $\mathrm{D},{ }^{\mathrm{g}} p<0.01$ from $\mathrm{C}$
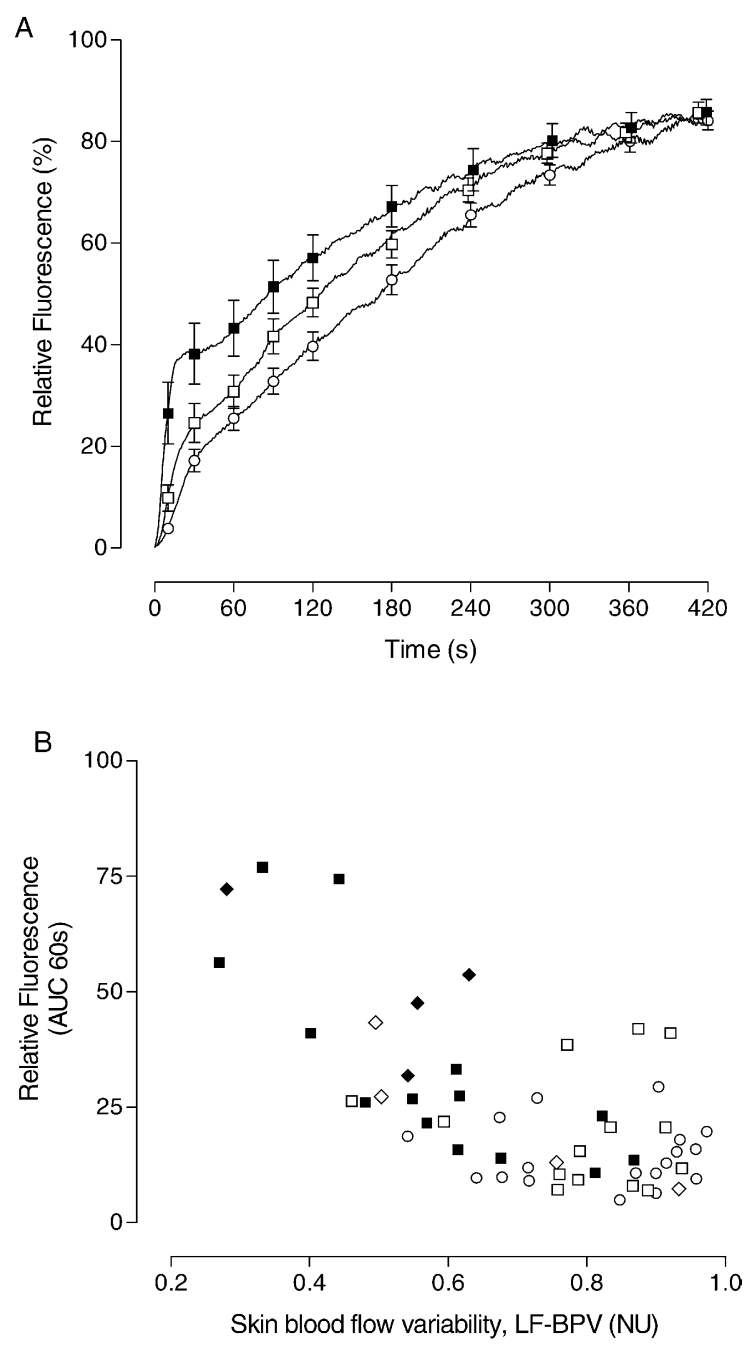

Fig. 3. (A) Fluorescence light intensity after sodium fluorescein arrival in the skin of diabetic patients with peripheral neuropathy $(\mathbf{\square})$, without peripheral neuropathy $(\square)$ and healthy controls ( $\bigcirc$ ). $\square$ vs. $\square, p<0.02 ; \mathbf{\square} v$. $\bigcirc, p<0.01$. (B) Relationship between the low frequency power of skin blood flow vari- normalized units, i.e. the ratio of LF-BFV/total BFV $(p<0.001$ from $\mathrm{D}$ and $\mathrm{C}$, Table 2$)$. The normalized LF-BFV was further evaluated in statistical analysis.

The number of visible skin capillaries was larger in $\mathrm{DN}$ than in $\mathrm{D}$ and $\mathrm{C}(p<0.05$, Table 2$)$. The $\mathrm{NaF}$ arrival time in the skin capillaries was shorter in DN than in D and C ( $p<0.001$ for both, Table 2). Maximal fluorescence was similar between the groups (Table 2). The NaF leakage curve of relative fluorescence from 0 to $420 \mathrm{~s}$, was higher in DN $(p<0.02$ from $\mathrm{D}$ and $p<0.005$ from C, Fig. 3A). Expressed as AUC's from 0 until 30,60, 120 and $420 \mathrm{~s}$, the differences in the $\mathrm{NaF}$ leakage were more pronounced in the first $60 \mathrm{~s}$ (Table 2). For practical purposes, therefore, the $\mathrm{NaF}$ leakage at $60 \mathrm{~s}\left(\mathrm{NaF}-\mathrm{AUC}_{60 \mathrm{~s}}\right)$ was taken for further analysis.

The normalized LF-BFV correlated with NaF$\mathrm{AUC}_{60 \mathrm{~s}}(r=-0.64, p<0.001, n=54$, Fig. 3B), diabetes duration $(r=-0.51, n=54, P<0.001)$, grade of retinopathy $(r=-0.51, p<0.001, n=54)$, combined sensorymotor nerve responses $(r=0.48, p<0.001, n=54), \mathrm{NaF}$ capillary arrival time $(r=-0.46, p<0.01, n=54)$, HbA1c concentration $(r=-0.44, p<0.01, n=54)$, skin temperature $(r=-0.43, p<0.01, n=54)$ and number of capillaries $(r=-0.33, p<0.02, n=54)$. The NaF-AUC 60 s correlated with the normalized LF-BPV $(r=-0.64, p<0.001$, $n=54)$, combined sensory-motor nerve responses $(r=-0.53, p<0.001, n=54)$, diabetes duration $(r=0.50$, $p<0.001, n=54), \mathrm{HbA}_{\mathrm{c}}$ concentration $(r=0.41, p<0.01$, $n=54), \mathrm{NaF}$ arrival time $(r=-0.40, p<0.01, n=54)$,

ability (LF-BFV) in normalized units and the area under the curve $60 \mathrm{~s}$ after sodium fluorescein arrival., Type 1 (ם) and Type $2(\diamond)$ diabetic patients with peripheral neuropathy, Type $1(\square)$ and Type $2(\leftarrow)$ diabetic patients without peripheral neuropathy and healthy controls $(\bigcirc), r=-0.64, p<0.001$ 
grade of retinopathy ( $r=0.38, p<0.01, n=54)$, the number of capillaries $(r=-0.36, p<0.01, n=54)$ and systolic blood pressure $(r=0.27, p<0.05, n=54)$.

Stepwise multiple regression analysis disclosed that when normalized LF-BPV, sensory-motor nerve responses, diabetes duration, $\mathrm{HbA}_{1 \mathrm{c}}$ concentration, grade of retinopathy, systolic blood pressure, $\mathrm{NaF}$ arrival time and number of capillaries were included as the determinants of $\mathrm{NaF}-\mathrm{AUC}_{60}$ s, only normalized LF-BFV and combined sensory-motor nerve responses independently contributed to $30 \% \quad(p<0.001)$ and $17 \%(p<0.01)$, respectively, to the variance in NaF$\mathrm{AUC}_{60 \mathrm{~s}}$. In a second analysis, sensory-motor nerve function, diabetes duration, grade of retinopathy and $\mathrm{HbA}_{1 \mathrm{c}}$ concentration were included as the determinants of normalized LF-BFV. Diabetes duration and combined sensory motor nerve responses explained $16 \%(p<0.01)$ and 9\% $(p<0.05)$, respectively, of the variance in normalized LF-BFV. The type of diabetes (Type 1/Type 2) and the use of an ACE-inhibitor (yes/no), included as categorical variables, did not change the multiple regression models of NaF$\mathrm{AUC}_{60 \mathrm{~s}}$ and LF-BFV.

\section{Discussion}

In this study a loss of sympathetically mediated vasomotion in the skin of diabetic patients with neuropathy was associated with an increased $\mathrm{NaF}$ leakage. This finding suggests that sympathetic nerves influence microvascular fluid homeostasis in a way that a loss of sympathetic function relates to an increased capillary permeability.

The power of the low-frequency component of blood flow variability, resembling sympathetic modulation, was decreased in the skin of the diabetic patients with peripheral neuropathy. Previous studies, using the laser Doppler flowmetry to record changes in skin blood flow documented blunted responses to sympathetic maneuvers in patients with diabetic neuropathy $[10,29,30,31,32]$. Another study [3] used spectral analysis on the signals of the laser Doppler, applied at the forearm and finger region, to demonstrate abnormalities in sympathetic modulation in diabetic patients with neuropathy. We extended these observations by measuring skin LF-BFV at the feet, where the long and thin unmyelinated sympathetic fibres are particularly vulnerable to neuronal damage by the diabetic state. Our finding that a reduction in skin LF-BFV power related to the grade of sensory-motor dysfunction as well as to the duration of diabetes, indicates that sympathetically mediated vasomotion decreases in conjunction with sensory-motor neuropathy and prolonged glycaemic exposure.

Capillary NaF leakage, taken as an index of capillary permeability, was increased in the diabetic patients with peripheral neuropathy. The amount of in- terstitial $\mathrm{NaF}$ is proportional to the rate of $\mathrm{NaF}$ diffusion through the skin capillaries [15, 21], since $\mathrm{NaF}$ delivery to the interstitial space is relatively fast, reaching a maximal interstitial concentration after 5 to $10 \mathrm{~min}$, while $\mathrm{NaF}$ clearance from the interstitium takes at least several hours. Estimation of the transcapillary escape rate of albumin $[13,16]$, the transcapillary diffusion gradient [14] and $\mathrm{NaF}$ leakage [15] showed an increase in capillary permeability in Type 1 diabetic patients, particularly when complicated by microalbuminuria. No previous studies have evaluated the role of neuropathy in the increased capillary permeability. Multiple regression analysis disclosed that a reduced LF-BFV and to lesser extent a loss of sensory-motor nerve function contributed to an increase in $\mathrm{NaF}$, independently from other covariates. Although microalbuminuria was highly prevalent among the patients with neuropathy, it was not related to a higher $\mathrm{NaF}$ leakage. A previously reported association between microalbuminuria and $\mathrm{NaF}$ leakage [15] could have had neuropathy as an important intermediary factor. In that study, neurography and blood flow variability were not measured, as ACE-inhibition therapy reduces $\mathrm{NaF}$ leakage [15], the true $\mathrm{NaF}$ leakage could have even been higher in the neuropathy group as more of these patients were on ACE-inhibitors. The finding that the use of an ACE-inhibitor did not contribute to the NaF leakage, does not exclude this possibility, but is probably beyond the scope of this study.

The following pathophysiological mechanisms could be involved in the relation between the decline in LF-BFV and the increased NaF leakage in the patients with neuropathy. According to Starlings forces of fluid filtration, the transcapillary passage of fluids depends on the transcapillary pressure gradient, which is a result of the net hydrostatic and the net osmotic pressures, the capillary filtration area and the diffusion coefficient [33]. The augmented $\mathrm{NaF}$ leakage can, therefore, be explained in terms of hydrostatic capillary pressure, the filtration surface area and barrier properties of the capillary wall [15]. The lower LFBFV could indicate a lower state of vasoconstriction of those skin blood vessels that are normally innervated by sympathetic nerves i.e. arterio-venous anastomoses and precapillary arterioles. Consequently, a reduced vasomotor tone might enhance skin blood flow as observed in this study by the higher skin temperature and the faster arrival and initial appearance of $\mathrm{NaF}$ in the skin capillaries of the patients with neuropathy. Indeed, an increased arterio-venous shunting and at the same time increased capillary perfusion, have been well documented in the foot skin of diabetic patients complicated by neuropathy $[9,10]$. The proposed precapillary arteriolar vasodilation could increase capillary hydrostatic pressure, which could have promoted $\mathrm{NaF}$ leakage.

The increased skin capillary density of the patients with neuropathy in this study [10] suggests that the re- 
duction in sympathetically mediated vasomotion is associated with capillary recruitment and, thereby, with a larger capillary filtration area for $\mathrm{NaF}$. Likewise, at the single capillary level, a decrease in the cyclic modulations of skin blood vessel constriction could, persistently or intermittently, increase the available capillary diffusion area. The diffusion coefficient could also have been altered in the patients with neuropathy. A decrease in cyclic modulations could have altered the properties of the capillary wall itself, by increasing the size of the intercellular cell junctions, through which NaF may pass. Taken together, probably an increased capillary filtration pressure, but more likely a larger capillary filtration area and a decreased capillary filtration barrier are proposed mechanisms, by which a reduced sympathetic tone promotes $\mathrm{NaF}$ leakage in the diabetic patient with peripheral neuropathy.

Early sympathetic dysfunction has been suggested to play a role in diabetes-associated haemodynamic alterations and has been implicated in the development of diabetic complications such as diabetic foot ulceration and diabetic nephropathy in patients with Type 1 diabetes mellitus and, although more controversial, in patients with Type 2 diabetes mellitus [33]. The fact that the multiple regression models of LF$\mathrm{BFV}$ and $\mathrm{NaF}$ leakage parameters of microcirculatory function were not influenced by the type of diabetes, challenges the thought that an increased capillary permeability in the skin is a phenomenon of autonomic neuropathy. Endothelial dysfunction could be common denominator of the observed association between $\mathrm{NaF}$ leakage and LF-BFV in these patients groups. Endothelial dysfunction, as demonstrated by a reduced vasodilation on the dorsal foot in response to heating and iontophoresis of acetylcholine, was found in neuropathic Type 1 and Type 2 diabetic patients both with and without vascular disease, but not in diabetic patients without neuropathy and control subjects [34]. Further, the vasodilatory response to acetylcholine at the foot was reduced in diabetic patient with neuropathy compared to diabetic patients without neuropathy and control subjects [35].

In this cross-sectional and observational study, we found a statistically independent contribution of skin LF-BFV on NaF leakage in diabetic patients complicated by neuropathy. Thus, these data add further insights in the factors contributing to the microcirculatory changes as described by the haemodynamic hypothesis $[11,33]$. Further studies are needed to elaborate the putative role of sympathetic nerve dysfunction on skin microcirculatory changes in patients with diabetes mellitus, and to evaluate whether these findings are also present in other organ tissues than the foot skin.

In conclusion, this study documents that peripheral autonomic neuropathy is related to increased capillary permeability in diabetic patients. A loss of sympathetic tone seems to be a major determinant of an increased capillary fluid filtration, which could be deleterious to the skin nutritive capillary function in diabetic patients with neuropathy.

Acknowledgements. We are indebted to Y. Talsma for her support during the neurography measurements. E. Blaauwwiekel, T. Links and J.-W. Meijer of the Beatrixoord Rehabilitation Centre of Haren which recruited many patients for the study. R. Henning carried out the statistical analysis of the sodium fluorescein curves. We thank M. Bruin, B. Buist, A. van Gessel, W. Kuipers and M. Teune for their skilful assistance at the vascular laboratory. Finally, the Groningen Endocrinology Foundation and the Keyzer en de Houtman Foundation provided financial support.

\section{References}

1. Christensen NJ (1969) Spontaneous variations in resting blood flow, postischaemic peak flow and vibratory perception in the feet of diabetics. Diabetologia 5:171-178

2. Benbow SJ, Pryce DW, Noblett K, MacFarlane IA, Friedmann PS, Williams G (1995) Flow motion in peripheral diabetic neuropathy. Clin Sci (Colch) 88:191-196

3. Bernardi L, Rossi M, Leuzzi S et al. (1997) Reduction of $0.1 \mathrm{~Hz}$ microcirculatory changes as evidence of sympathetic dysfunction in insulin-dependent diabetes. Cardiovasc Res 34:185-191

4. Wiensperger N (2000) Defects in microvascular haemodynamics during prediabetes: contributor or epiphenomenon? Diabetologia 43:1439-1448

5. Wiernsperger NF (2001) In defense of microvascular constriction in diabetes. Clin Hemorheol Microcirc 25:55-62

6. Hoffman RP, Sinkey CA, Kienzle MG, Anderson EA (1993) Muscle sympathetic nerve activity is reduced in IDDM before overt autonomic neuropathy. Diabetes 42:375-380

7. Schnell O, Kirsch CM, Stemplinger J, Haslbeck M, Standl E (1995) Scintigraphic evidence for cardiac sympathetic dysinnervation in long-term IDDM patients with and without ECG-based autonomic neuropathy. Diabetologia 38:1345-1352

8. Ziegler D, Weise F, Langen KJ et al. (1998) Effect of glycaemic control on myocardial sympathetic innervation assessed by [123I]metaiodobenzylguanidine scintigraphy: a 4-year prospective study in IDDM patients. Diabetologia 41:443-451

9. Flynn MD, Edmonds ME, Tooke JE, Watkins PJ (1988) Direct measurement of capillary blood flow in the diabetic neuropathic foot. Diabetologia 31:652-656

10. Netten PM, Wollersheim H, Thien T, Lutterman JA (1996) Skin microcirculation of the foot in diabetic neuropathy. Clin Sci (Colch) 91:559-565

11. Sandeman DD, Shore AC, Tooke JE 1992) Relation of skin capillary pressure in patients with insulin-dependent diabetes mellitus to complications and metabolic control. N Engl J Med 327:760-764

12. Bollinger A, Frey J, Jäger K, Furrer J, Seglias J, Siegenthaler W (1982) Patterns of diffusion through skin capillaries in patients with long-term diabetes. N Engl J Med 307:13051310

13. Feldt-Rasmussen B (1986) Increased transcapillary escape rate of albumin in Type 1 (insulin-dependent) diabetic patients with microalbuminuria. Diabetologia 29:282-286 
14. Jaap AJ, Shore AC, Gartside IB, Gamble J, Tooke JE (1993) Increased microvascular fluid permeability in young Type 1 (insulin-dependent) diabetic patients. Diabetologia 36:648-652

15. Oomen PHN, Jager J, Hoogenberg K, Dullaart RPF, Reitsma WD, Smit AJ (1999) Capillary permeability is increased in normo- and microalbuminuric Type 1 diabetic patients: amelioration by ACE-inhibition. Eur J Clin Invest 29:1035-1040

16. Vervoort G, Lutterman JA, Smits P, Berden JH, Wetzels JF (1999) Transcapillary escape rate of albumin is increased and related to haemodynamic changes in normo-albuminuric type 1 diabetic patients. J Hypertens 17:1911-1916

17. Bernardi L, Rossi M, Fratino P, Finardi G, Mevio E, Orlandi C (1989) Relationship between phasic changes in human skin blood flow and autonomic tone. Microvasc Res 37:16-27

18. Bernardi L, Radaelli A, Solda PL et al. (1996) Autonomic control of skin microvessels: assessment by power spectrum of photoplethysmographic waves. Clin Sci (Colch) 90:345-355

19. Cunha-Vaz J, Faria de Abreu JR, Campos AJ (1975) Early breakdown of the blood-retinal barrier in diabetes. Br J Ophthalmol 59:649-656

20. Frey J, Furrer J, Bollinger A (1983) Transcapillary diffusion of Na-fluorescein in skin areas of the dorsum of the foot in juvenile diabetics. Schweiz Med Wochenschr 113:1964-1969

21. Jager J, Oomen PHN, Sluiter WJ, Reitsma WD, Smit AJ (1997) Improved reproducibility of the 'large-window' method of assessing transcapillary and interstitial fluorescein diffusion in the skin in healthy subjects and in subjects with insulin-dependent diabetes mellitus. Int J Microcirc Clin Exp 17:150-158

22. Report and recommendations of the San Antonio Conference on diabetic neuropathy (1988) Diabetes 37:1000-1004

23. Dyck PJ (1998) Detection, characterization and staging of polyneuropathy: assesses in diabetics. Muscle Nerve 11:21-32

24. Meijer JW, Van Sonderen E, Blaauwwiekel EE et al. (2000) Diabetic neuropathy examination: a hierarchical scoring system to diagnose distal polyneuropathy in diabetes. Diabetes Care 23:750-753
25. Standardized measures of diabetic neuropathy

(1995) Diabetes Care 18 [Suppl 1]:59-82

26. Netten PM, Keeris LM, De Boo T, Wollersheim H, Thien T (1993) A clinical comparison of two laser-Doppler instuments. Int J Microcirc Clin Exp 12:185-192

27. Robbe HW, Mulder LJ, Ruddel H, Langewitz WA, Veldman JB, Mulder G (1997) Assessment of baroreceptor reflex sensitivity by means of spectral analysis. Hypertension 10:538-543

28. Lefrandt JD, Hoogenberg K, Van Roon AM, Dullaart RPF, Gans ROB, Smit AJ (1999) Baroreflex sensitivity is depressed in microalbuminuric Type I diabetic patients at rest and during sympathetic manoeuvres. Diabetologia 42:13451349

29. Aso Y, Inukai T, Takemura Y (1997) Evaluation of skin vasomotor reflexes in response to deep inspiration in diabetic patients by laser Doppler flowmetry. Diabetes Care 20:1324-1328

30. Stansberry KB, Hill MA, Shapiro SA, McNitt PM, Bhatt BA, Vinik AI (1997) Impairment of peripheral blood flow responses in diabetes resembles an enhanced aging effect. Diabetes Care 20:1711-1716

31. Bornmyr S, Castenfors J, Svensson H et al. (1999) Detection of autonomic sympathetic dysfunction in diabetic patients. A study using laser Doppler imaging. Diabetes Care 22:593-597

32. Bornmyr S, Castenfors J, Svensson H, Wroblewski M, Sundkvist G, Wollmer P (2000) Abnormal vasoreaction to arousal stimuli - an early sign of diabetic sympathetic neuropathy demonstrated by laser Doppler flowmetry. J Clin Neurophysiol 17:419-425

33. Tooke JE (1995) Microvascular function in human diabetes. A physiological perspective. Diabetes 44:721726

34. Veves A, Akbari CM, Primavera J et al. (1998) Endothelial dysfunction and the expression of endothelial nitric oxide synthetase in diabetic neuropathy, vascular disease, and foot ulceration. Diabetes 7:457-463

35. Arora S, Smakowski P, Frykberg RG et al. (1998) Differences in foot and forearm skin microcirculation in a group of Type 1 and Type 2 diabetic patients with and without neuropathy. Diabetes Care 8:1339-1344 